\title{
Processing-structure-property relationships of electrospun PLA-PEO membranes reinforced with enzymatic cellulose nanofibers
}

\author{
Robab Ghafari $^{\mathrm{a}}$, Roberto Scaffaro ${ }^{\mathrm{b}, *}$, Andrea Maio ${ }^{\mathrm{b}}$, Emmanuel F. Gulino ${ }^{\mathrm{b}}$, Giada Lo Re ${ }^{\mathrm{c}}$, \\ Mehdi Jonoobi ${ }^{\text {a }}$,** \\ ${ }^{a}$ Department of Wood and Paper Science and Technology, Faculty of Natural Resources, University of Tehran, Karaj, Iran \\ ${ }^{\mathrm{b}}$ Department of Engineering, University of Palermo, Viale delle Scienze, Ed. 6, 90128, Palermo, Italy \\ ${ }^{c}$ Department of Industrial and Materials Science, Division of Engineering Materials, Chalmers University of Technology, SE-412 96, Gothenburg, Sweden
}

\section{A R T I C L E I N F O}

Keywords:

Polylactic acid

Polyethylene oxide

Nanocellulose

Bionanocomposites

Electrospinning

Raman spectroscopy

\begin{abstract}
A B S T R A C T
Three different solvent mixtures were used to prepare electrospun membranes based on polylactic acid (PLA), polyethylene oxide (PEO) and enzymatic cellulose nanofibers (CNF). The materials were characterized from a morphological, spectroscopic, mechanical and rheological point of view. Furthermore, swelling test were performed in order to assess the water uptake of each sample.

The results put into evidence that the choice of the solvents affects the structure and the properties of the membranes. Among the protocols tested, using chloroform/acetone/ethanol mixture was found to allow a high degree of CNF dispersion and a good electrospinnability of polymer solutions. These features led to membranes with impressive improvement of mechanical properties $(+350 \%$ in stiffness, $+350 \%$ in tensile strength and $+500 \%$ in toughness) with respect to those of PLA/PEO and dramatically increased the water uptake of these materials (up to $+350 \%$ within $120 \mathrm{~min}$ ).
\end{abstract}

\section{Introduction}

In recent years, the development of bionanocomposites has attracted both industrial and academic attention because of increasing interest on developing new sustainable and ecofriendly materials, in the perspective of preventing the accumulation of plastics waste [1-3]. One of the most promising and widespread biopolymers is polylactic acid (PLA), which presents many advantages such as renewability, compostability, biocompatibility, high transparency, availability in the market, excellent tensile strength and stiffness equivalent to some commercial oil-based polymers [4-10]. PLA is a linear aliphatic thermoplastic polyester derived from $100 \%$ renewable resources such as sugar, corn, potatoes, cane, beet, etc. that presents a fragile behavior with relatively high elastic modulus and low elongation at break [6,7]. Nevertheless, there are some disadvantages, such as its high brittleness, slow crystallization behavior, poor biodegradability and low gas barrier properties that may limit its current use in some application fields [9-14]. Among the strategies to improve PLA toughness, adding a second polymer as a plasticizer, such as polyethylene glycol (PEG) or polyethylene oxide
(PEO), is suitable. Beyond the mechanical performance, these latter polymers allow also improving cytocompatibility and biodegradability, as requested by high values applications of PLA, i.e. medical devices [15, 16].

Polymer fibers represent an emerging class of biomimetic structures that have shown tremendous promises as tissue scaffolds, modern wound dressings and advantageous drug delivery systems $[9,10]$. To date, three processing techniques, self-assembly, phase separation and electrospinning have been developed, with the latter method showing the greatest potential $[9,10]$. Electrospinning is a simple and versatile method to prepare ultrathin fibers ranging from micro-to nano-meter range diameters from polymer solutions or melts. Electrospun membranes show high porosity and high specific surface, as well as tunable mechanical properties and topological features [7].

Electrospinning attracts considerable attention due to its simplicity, high efficiency, and desirable microstructure (e.g., porosity), especially for PLA-based systems [15]. However, neat PLA electrospun fibers show some drawbacks, such as weak mechanical properties and low thermal stability, thus limiting their industrial applications. Enhancing the

\footnotetext{
* Corresponding author.

** Corresponding author.

E-mail addresses: roberto.scaffaro@unipa.it (R. Scaffaro), mehdi.jonoobi@ut.ac.ir (M. Jonoobi).
} 
mechanical performance of electrospun PLA nanofibers is highly desired for consumer applications, especially for PLA-based fibers that are requested to meet controllable mechanical requirements during transportation, reprocessing, and recovery. In this regard, several scientific researches focused on the process and on post-process modifications such as the use of multiple jet [17], fibers alignment [18], surface modifications [19], blends with other biopolymers [20] and/or the use of nanoparticles (NPs) [21].

Optimization of electrospinning configuration and operating conditions strongly differs, depending on the type of solvents. The main factors influencing the electrospinning configuration (jet initiation and jet continuation) are: (i) processing parameters, such as applied electric field, needle-to-collector distance, flow rate and type of collector, (ii) chemical-physical properties of the components, affecting solution/melt properties and therefore electrospinnability, such as viscosity, surface tension and conductivity [22].

Cellulose is the most abundant organic compound obtained from biomass. Recently, it has been used for a broad range of applications, due to the increasing demand for environmentally friendly and biocompatible products and owing to its attractive structures and unique properties [23]. Among these, biocompatibility, hydrophilicity and biodegradability render cellulose a suitable material in the biomedical field [24]. In chronic wound dressing, it has been observed to supply a moist environment for healing process due to its ability to absorb water [25]. It displays high versatility, since it can be used either as a polymer (i.e. in its raw form) or as a nanofiller (via isolation of the crystalline domains from cellulose sources) [26,27]. Nanocellulose refers to cellulose fibrils, whose diameters are in the magnitude of nanometers. Beyond the obvious advantages in terms of sustainability and non-toxicity, using cellulose nanofibrils (CNFs) provides access to several attractive features including remarkable stiffness and strength in combination with high specific surface area and high aspect ratio [28]. In fact, consistently with the scientific literature data, the intrinsic properties of CNF films, such as elastic moduli in the order of $10-17 \mathrm{GPa}$ and tensile strengths between 130 and $250 \mathrm{MPa}$, makes CNF very promising as nanofillers for polymeric composites [28,29]. Enzymatic CNFs are prepared by virtue of suitable enzymes that catalyze the reaction of water with cellulosic biomass thus leading to shorter chains [30].

Enzymatic CNFs possess fascinating structure, characterized by extremely high aspect ratios, being the diameters in the order of few nanometers and the lengths in the micrometers scale. However, the level of CNF dispersion strongly affects the rheological behavior in water or other solvents [23,31]. Often, CNF is chemically functionalized in order to improve its affinity to polymer matrices and obviously to the solvents usually employed for the preparation of nanocomposites [6]. However, beyond the issues associated to the use of chemical reactants and to the long-time consuming reactions, the chemical derivatization of CNF may affect its hydrophilicity, which is crucial for all those biological/biomedical applications requiring a high level of cytocompatibility.

In this work, we propose a novel and easy approach to prevent CNF aggregation without using any functionalization route. It was investigated the possibility to use a three-solvent mixture to prepare electrospun membranes based on PLA, PEO and CNF aiming to ensure both the dispersability of nanoparticles and the electrospinnability of the polymers.

\section{Materials and methods}

\subsection{Materials}

PLA 2002D (Mw $215 \mathrm{kDa}$; D-lactide content 4\%) was purchased from NatureWorks. PEO (Mw $100 \mathrm{kDa}$ ), acetone (Ac), chloroform (CF), ethanol (EtOH), diethyl ether and water were purchased from Sigma Aldrich. All the reactants were ACS grade (purity $>99 \%$ ) and used as received.

\subsection{Extraction and preparation of enzymatic-CNF}

The pulp usually used for best performances in enzymatic reactions should have undergo no drying treatments and therefore, a never-dried pulp (supplied by Nordic Paper, Sweden) with $13.8 \mathrm{wt} \%$ hemicelluloses and $0.7 \mathrm{wt} \%$ lignin was chosen to prepare enzymatic-CNF. After an enzymatic pretreatment (Novozym 476) it was passed eight times through a microfluidizer (Microfluidics Inc., USA), as reported in a previous study [32]. A viscous water colloidal dispersion ( $\sim 1.6 \mathrm{wt} \%$ dry content) of enzymatic-CNF was obtained from the last pass through a microfluidizer. The nanofibrils diameter distribution was in the range 4-22 nm [31].

\subsection{Preparation of the membranes}

Binary (PLA/PEO) and ternary (PLA/PEO/CNF) fibrous membranes were prepared by electrospinning. All the samples contain PLA and PEO (3:1), while differing each other for the presence or the absence of CNF ( $1 \mathrm{wt} \%$ ) and for the composition of the solvent mixture. In the alphanumeric codename of each material the letter refers to the type of solvent mixture used, with $\mathrm{A}, \mathrm{B}$ and $\mathrm{C}$ respectively indicating $\mathrm{CF} / \mathrm{Ac}(4: 2)$, $\mathrm{CF} / \mathrm{EtOH}$ (4:2), and $\mathrm{CF} / \mathrm{Ac} / \mathrm{EtOH}$ (4:1:1); whereas the number (0 or 1 ) refers to the loading level of CNF. The formulation of the samples is listed in Table 1, together with the operating conditions adopted.

Schematics of the preparation protocols followed are provided in Fig. 1. In the case of binary blends (A0, B0, C0), the polymeric solutions (10 wt $\%$ ) were achieved by vigorous stirring, whereas for corresponding ternary membranes (A1, B1, C1), an ultrasonication step (2h) was performed prior to stirring in order to disperse CNF. In all the cases, the resulting solutions were poured into $10 \mathrm{ml}$ glass syringe equipped with a 19G stainless steel needle and electrospun by a conventional electrospinning equipment (Linari Engineering-Biomedical Division, Italy) at $\mathrm{T}=25{ }^{\circ} \mathrm{C}$ and $40 \% \mathrm{RH}$. Flow rate $(1.19 \mathrm{ml} / \mathrm{h})$, supplied high voltage $(15 \mathrm{kV})$, tip-to-collector distance $(10 \mathrm{~cm})$ were kept as constants for each sample. The nanofibers were collected on a grounded collector wrapped in an aluminum foil. The process was performed for $30 \mathrm{~min}$ in order to obtain membranes approximately $25 \mu \mathrm{m}$ thick. Finally, the membranes were coagulated in diethyl ether in order to remove any residual solvent.

\subsection{Characterization techniques}

$\mu$-Raman spectroscopy was performed by means of a Renishaw InVia instrument, with diode laser excitation at $633 \mathrm{~nm}$ and spectral resolution equal to $1 \mathrm{~cm}^{-1}$. Measurements in at least five different sample positions have been repeated for each treatment. Spectra were collected in the spectral range of interest:1000-1250 $\mathrm{cm}^{-1}$. More details can be found in our previous reports $[33,34]$.

Transmission electron microscopy (TEM) imaging was carried out using a Hitachi HT7700 TEM at $100 \mathrm{kV}$ accelerating voltage. Enzymatic CNF aqueous dispersion was deposited onto hollow carbon-coated 400 mesh copper grids (TED PELLA, USA) and observed after drying at room temperature overnight.

SEM analysis (Phenom ProX, Phenom-World, The Netherlands) was

Table 1

Formulation of the samples prepared.

\begin{tabular}{llll}
\hline Sample & PLA/PEO ratio & CNF (wt\%) & CF: Ac: EtOH ratio \\
\hline A0 & $75 / 25$ & - & $4: 2: 0$ \\
B0 & $75 / 25$ & - & $4: 0: 2$ \\
C0 & $75 / 25$ & - & $4: 1: 1$ \\
A1 & $75 / 25$ & 1 & $4: 2: 0$ \\
B1 & $75 / 25$ & 1 & $4: 0: 2$ \\
C1 & $75 / 25$ & 1 & $4: 1: 1$ \\
\hline
\end{tabular}



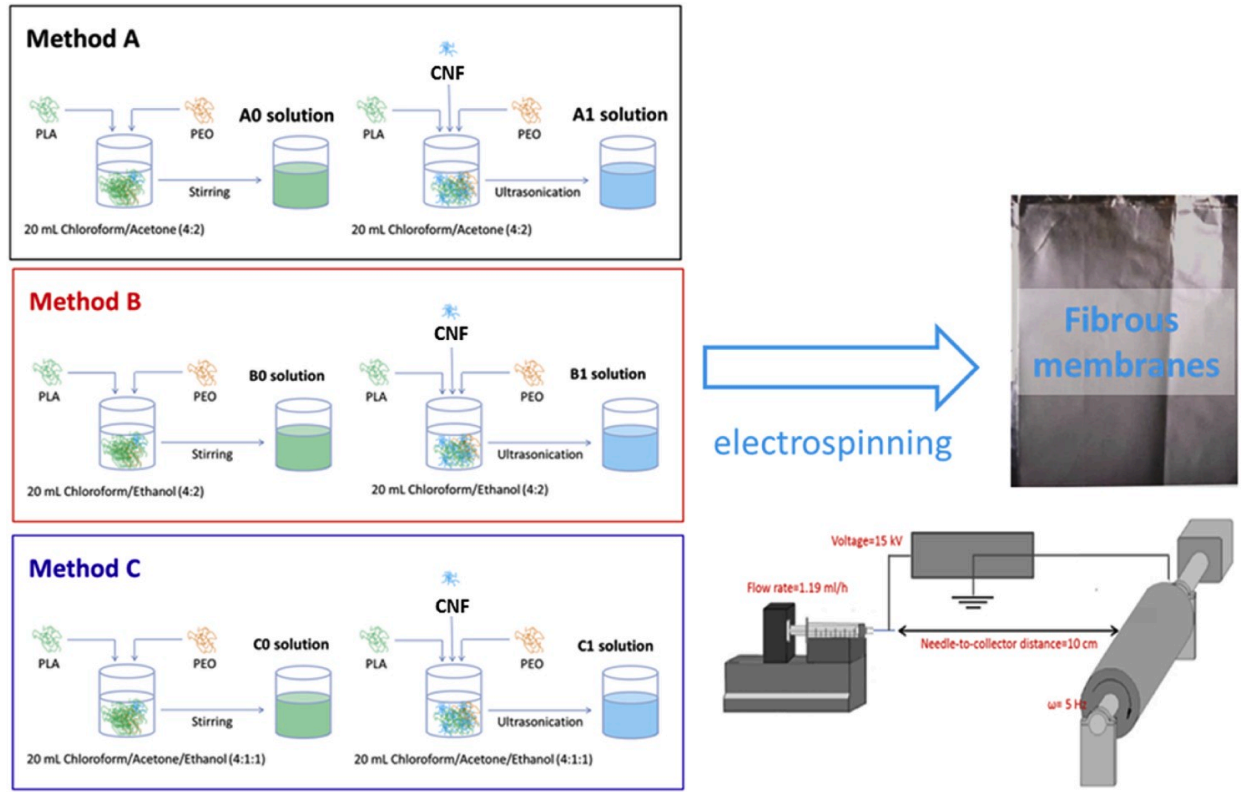

Fig. 1. Schematics of the process.

carried out to study the morphology of nanofibrous mats, which were attached on an aluminum stub using an adhesive carbon. Fiber diameter size distribution was determined using Diameter $J$, which is a plugin of Image $\mathrm{J}$ software [35]. More details can be found in our previous reports $[36,37]$.

Rheological behavior of the solutions was investigated by using a rotational rheometer (Mars, Thermofisher) in oscillatory frequency sweep mode using a $25-\mathrm{mm}$ parallel-plate geometry. The measurements were performed at $25^{\circ} \mathrm{C}$ at a constant stress of $1 \mathrm{~Pa}$, within the angular frequency range $1-100 \mathrm{rad} / \mathrm{s}$.

Tensile tests were performed by using a dynamometer (Instron 3365, UK) equipped with a $1 \mathrm{kN}$ load cell on rectangular shaped specimens $(10 \mathrm{~mm} \times 90 \mathrm{~mm})$ cut off from the mats. Owing to the high stretchability of the samples, the measurements were performed by using a double crosshead speed: $1 \mathrm{~mm} / \mathrm{min}$ for $2 \mathrm{~min}$ and $50 \mathrm{~mm} / \mathrm{min}$ until fracture occurred. The grip distance was set to $20 \mathrm{~mm}$, whereas the sample thickness was measured before each measurement. The representative stress-strain curves were reported for each material, as well as the main properties derived from the mechanical tests. In detail, elastic modulus (E) was calculated as the slope of stress-strain curve extrapolated at zero-strain, tensile strength (TS) and elongation at break (EB) were respectively taken as the maximum values of stress and strain recorded during the tests, toughness was measured as the integrated area of each stress-strain curve. Being the tests performed on 10 replicates, E, TS, EB and toughness were provided as average values \pm standard deviations.

Swelling tests were performed by immersing in water pre-weighed samples and the water uptake at various time intervals, swelling percentage (S), was assessed as reported in Equation (1):

$S=\frac{W_{t}-W_{0}}{W_{t}} \times 100$

where $W_{t}$ and $W_{0}$ respectively indicate the weight measured at a given time interval and the initial weight.

\section{Results and discussion}

The morphological analysis of CNFs is reported in Fig. 2. Fig. 2A shows a TEM micrograph of CNFs deposited onto a carbon-coated copper grid, whereas diameter distribution of nanofibrils is reported in
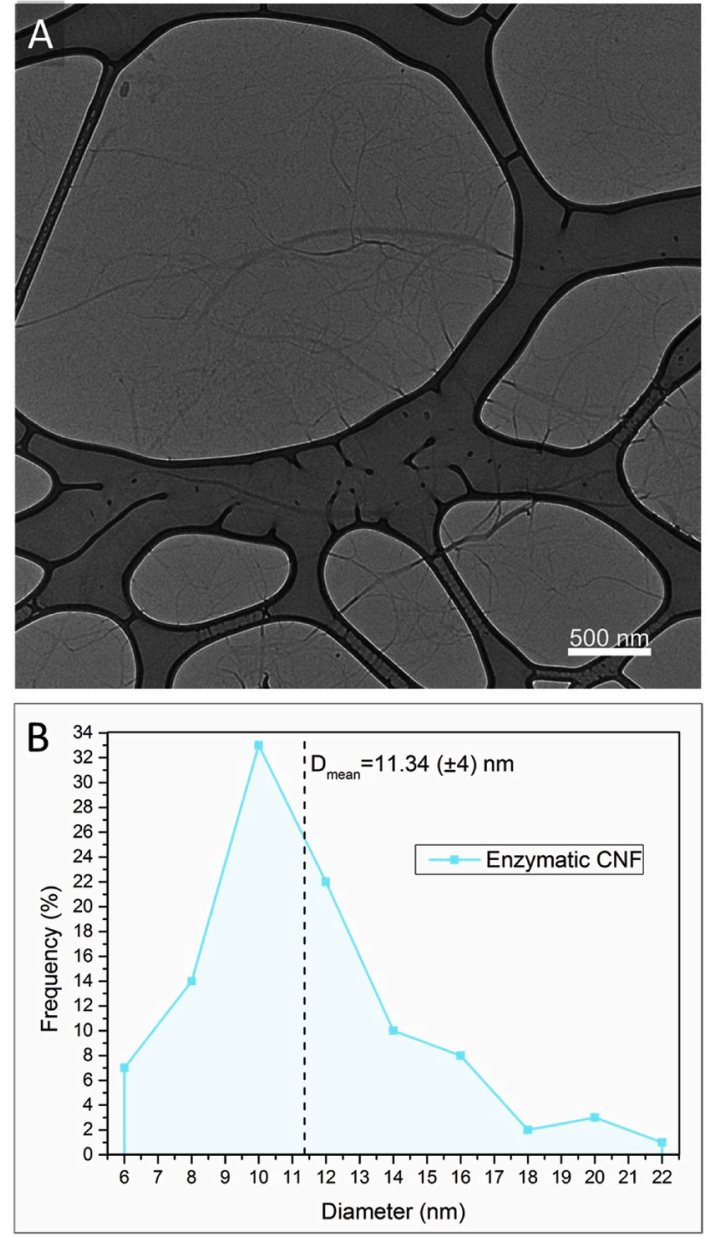

Fig. 2. TEM micrograph of enzymatic CNF (A); diameter distribution of nanofibrils based on 100 measurements, together with mean value and standard deviation. 
Fig. 2B. CNFs were found in the form of both individualized nanofibrils and some bundles. Diameter distribution, based on 100 measurements, indicated a unimodal distribution, whose maximum was centered at $10 \mathrm{~nm}$, with an average value of $11.43 \mathrm{~nm}$ and a standard deviation of $4.0 \mathrm{~nm}$.

The crucial role of viscosity in electrospinning has been widely elucidated [22]. Furthermore, the choice of the solvents, on one hand, affects the viscosity of polymeric solutions with direct consequence on their spinnability and, on the other hand, may influence the dispersion level of CNFs. It was studied the rheological behavior of the solutions/dispersions, and the results are provided in Fig. 3. As one can see, rheology of PLA/PEO is shown to vary depending on the solvent mixture used: $\mathrm{A} 0$ and $\mathrm{CO}$ displayed a non-Newtonian behavior in all the frequency range investigated, whereas B0 was found to behave as a Newtonian fluid at frequencies higher than $2 \mathrm{rad}^{-1} \mathrm{~s}^{-1}$. Furthermore, viscosity of $\mathrm{A} 0$ was found to be higher than that of $\mathrm{C} 0$, but however comparable, that of B0 proved to be dramatically lower. Nevertheless, when 1\% CNF is added, $\mathrm{C} 1$ becomes more viscous than $\mathrm{A} 1$ in all the frequency range, with this latter phenomenon being attributable to the higher dispersion degree of cellulose in chloroform/acetone/ethanol solution. In fact, CNF suspensions are very viscous liquids formed by a 3D maze of entangled nanofibrils [9].

B1 viscosity proved to be dramatically lower than A- and C-series samples but it is worth noting that $\mathrm{B} 1$ displays viscosity values higher than $\mathrm{B} 0$, especially in the low frequencies range, where the presence of yield stresses is clearly detectable, thus suggesting a remarkable effect of $\mathrm{CNF}$, likely symptomatic of a high dispersion degree.

Fig. 4 provides a survey view of the morphology of samples achieved according to the three different preparation routes. Depending on the choice of solvents, it is possible to achieve different structures: A-series and C-series samples are nanofibrous mats, whereas B-series materials present both electrosprayed areas and electrospun fibers. However, for these latter samples, we selected zones characterized by electrospun fibers aiming to analyze the salient features of the fibers and to compare the samples each other. SEM micrographs of the samples at higher magnification are provided in Fig. 5, fibers diameter distribution is shown in Fig. 6. The results reveal that fibers are randomly oriented, and their diameters are in the microscale range for all the investigated systems. Among the binary blend mats, $\mathrm{C} 0$ proved to be the most regular one, displaying a smooth surface and the narrowest diameter distribution. A0 displayed similar features, with a slight broadening in fibers diameter size distribution, however a unimodal distribution with a maximum centered at $1.1 \mu \mathrm{m}$ was found for $\mathrm{A} 0$ and $\mathrm{C} 0$. By contrast, B0 displayed the presence of blobs, with a thickening of mean diameter,

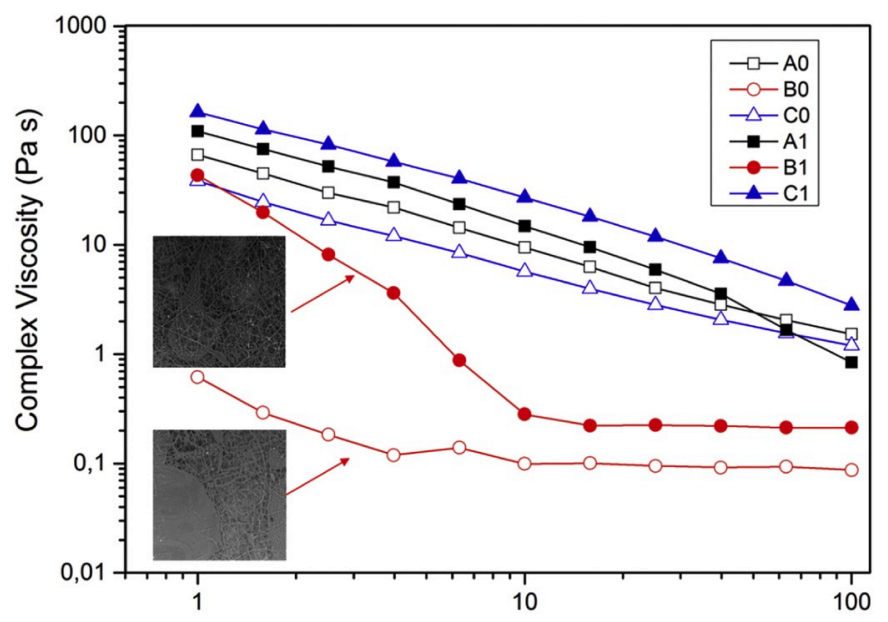

Angular frequency $\left(\mathrm{rad} \mathrm{s}^{-1}\right)$

Fig. 3. Complex viscosity curves of the samples prepared. characterized by many interconnections among the fibers. This phenomenon usually takes place whether the coalescence of the fibers into a unique structure occurs before solvent evaporation and solidification of polymeric structure [38]. It is worth noting that a survey morphology of B-series samples reveals the presence of electrospraying phenomena, independently from the presence of filler. This issue can be attributable to the presence of ethanol, which is not appropriate for electrospinning of PLA/PEO blends, as envisaged by rheological results previously discussed.

As regards the nanocomposites, $\mathrm{A} 1$ and $\mathrm{C} 1$ present a uniform morphology, even if in A1 few blobs were detected, with a slight thickening of fibers mean diameter and a broader distribution. Similarly to what observed for B0, even B1 displayed the coexistence of electrospraying and electrospinning phenomena but in this case the latter phenomenon prevails on the former one. Bright dots, reasonably attributable to PEO islands [39], are spotted in all the samples but especially in B1, likely due to the insolubility of PEO in ethanol [40]. Raman analysis was used to qualitatively detect the presence of CNF, whose direct observation in polymer-based nanocomposites is problematic, due to the extremely low dimensions of nanoparticles and microscopy detection limits $[41,42]$. Fig. 7 reports $\mu$-Raman spectra in the region $1000-1250 \mathrm{~cm}^{-1}$ collected for $\mathrm{C} 0, \mathrm{CNF}$ and $\mathrm{C} 1$ (those referring to the comparison between $\mathrm{A} 0$ and $\mathrm{A} 1$ and between $\mathrm{B} 0$ and $\mathrm{B} 1$ are similar). This spectral region is extremely variegated due to the presence of $\mathrm{C}-\mathrm{O}$ bonds in PLA, PEO and CNF. CNF displays three well-detectable peaks. Among these, the strong band centered at $1096 \mathrm{~cm}^{-1}$ is traditionally assigned to stretching vibration of $\mathrm{C}-\mathrm{O}$ bond (coupled with $\mathrm{C}-\mathrm{C}$ ) and refers to the cellulose crystallinity, whereas the modes centered at $1120 \mathrm{~cm}^{-1}$ and $1150 \mathrm{~cm}^{-1}$ are respectively ascribed to vibration stretching of C-O ring and C-OH bonds $[19,20]$. C0 presents a variegated spectrum characterized by a bunch of overlapped bands, with three main peaks located at $1049 \mathrm{~cm}^{-1}, 1090 \mathrm{~cm}^{-1}, 1125 \mathrm{~cm}^{-1}$, attributable to PLA phase, and respectively indicating vibration stretching of $\mathrm{C}-\mathrm{CH}_{2^{-}}, \mathrm{C}-\mathrm{O}$ and $\mathrm{CH}_{3}$ rocking [43]. A closer inspection of this spectrum enables detecting less intense signals attributable to $\mathrm{PEO}$ phase, such as the shoulders located at 1048,1051 and $1072 \mathrm{~cm}^{-1}$, and the overlapped mode in the range $1225-1250 \mathrm{~cm}^{-1}$, which refer to polymorphic crystallinity of PEO [44-46]. More in particular, these bands arise from the coexistence of PEO chains arranged into a planar zigzag all-trans configuration and in a helicoidal monocline crystalline structure composed of sequences of trans-trans-gauche conformations, even if in this case the signals are quite weak [44-46].

In the case of $\mathrm{C} 1$ sample, beyond the main peaks of PLA, it is possible to clearly observe those of PEO phase, reasonably indicating a polymorphic crystallinity somehow enhanced. Notably, the typical bands of CNF are detected, thus confirming the successful incorporation of CNF into the PLA/PEO matrix. Furthermore, for $\mathrm{C} 1$ the insurgence of new absorption bands in the spectral range $1190-1225 \mathrm{~cm}^{-1}$ could be an indicator of good matrix-filler interaction. This aspect would deserve an ad hoc dedicated study, since the investigation of interphase in PLA/ $\mathrm{PEO} / \mathrm{CNF}$ via Raman spectroscopy is still lacking in the scientific literature.

In order to assess the effect of preparative on the performance of samples, mechanical tests were carried out and the results are provided in Fig. 8. Representative stress-strain curves of the samples investigated are shown in Fig. 8A, whereas a close-up of low strains region of the curves is provided in Fig. 8B. Main results derived from tensile tests, i.e. elastic modulus (E), tensile strength (TS), elongation at break (EB) and toughness are listed in Table 2. By examining representative stress-strain curves it can be noted that all the samples show a ductile behavior with a well-defined necking region followed by a plateau in the plastic deformation for all the samples except for $\mathrm{C} 1$, which displayed strain hardening. However, mechanical properties of each sample are found to be dramatically affected by both type of preparation and formulation. As regards binary systems, TS and $\mathrm{EB}$ values follow the order: $\mathrm{A} 0>\mathrm{CO}>\mathrm{B} 0$. The effect of adding CNF is found to vary, depending on the preparative. 

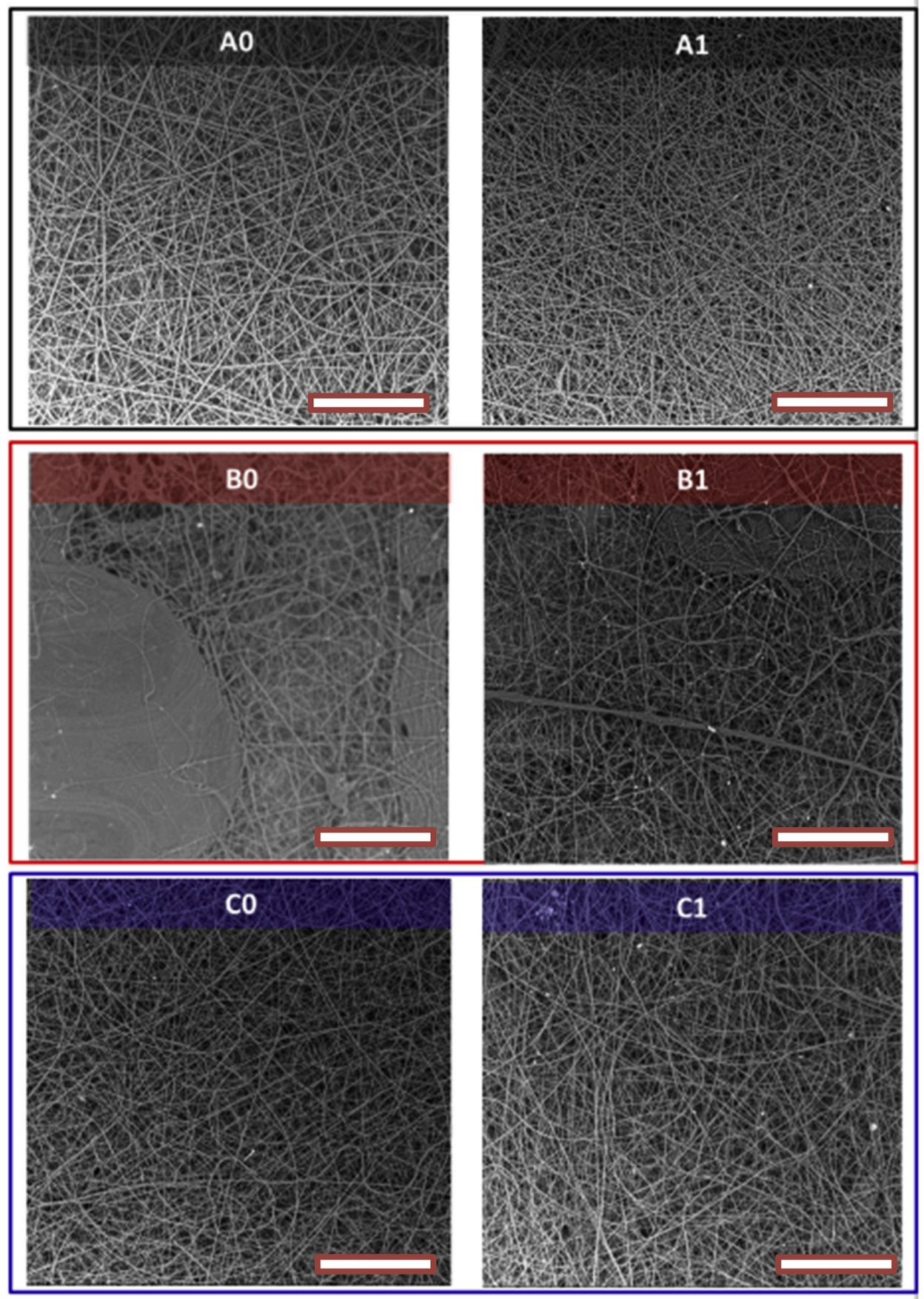

Fig. 4. Survey view of structures achieved at the different conditions (scale bar $=80 \mu \mathrm{m}$ ).

In fact, in A-series and B-series materials, incorporation of CNF, somehow enhanced the stretchability of PLA/PEO, being detrimental to TS. In the case of C-series samples, instead, the presence of the filler determines a huge increase of TS without significantly altering EB. By analyzing the initial slope of stress-strain curves (Fig. 8B), it can be seen that $\mathrm{A} 0$ and $\mathrm{CO}$ display similar stiffness, while $\mathrm{B} 0$ presents a lower E value. Adding CNF is shown to have negligible effects in A- and B-series materials, while determining a clear increase in the stiffness of $\mathrm{C} 1$. The quantitative analysis of $\mathrm{E}$, provided in Table 2, pointed out that, depending on preparative, stiffness of fibrous membranes having the same formulation was found to vary from $15 \mathrm{MPa}$ for B1 to $155 \mathrm{MPa}$ for $\mathrm{C} 1$ (i.e. 10 -fold), TS proved to increase from 1 to $5.4 \mathrm{MPa}$ (540\%), EB from to $30-31 \%$ (for B1 and C1) to 74\% (for A1), i.e. more than two-fold. A1 and C1 membranes display exceptionally high values of work to fracture (1.37 and $1.41 \mathrm{MJ} / \mathrm{m}^{3}$, respectively) with respect to $\mathrm{B} 1$ $\left(0.28 \mathrm{MJ} / \mathrm{m}^{3}\right)$, indicating a clear positive effect of the addition of CNF on the membrane toughness, if added in a suitable formulation/ preparative.

Aiming to highlight the effect of CNF, the reduced tensile properties are calculated for each preparative, by dividing the generic property of nanocomposite to that of corresponding matrix. The results are reported in Fig. 9. It is clearly visible that C-method allows CNF to exert a huge reinforcing effect, since $\mathrm{C} 1$ shows increments with respect to those of $\mathrm{C} 0$ in terms of stiffness (350\%), tensile strength (400\%) and toughness (500\%) while being practically preserved the stretchability. As regards A and B methods, instead, negligible or detrimental changes in all the properties were found, except for the enhanced stretchability and toughness of A1 when compared to A0 (200\% and 137\%). 

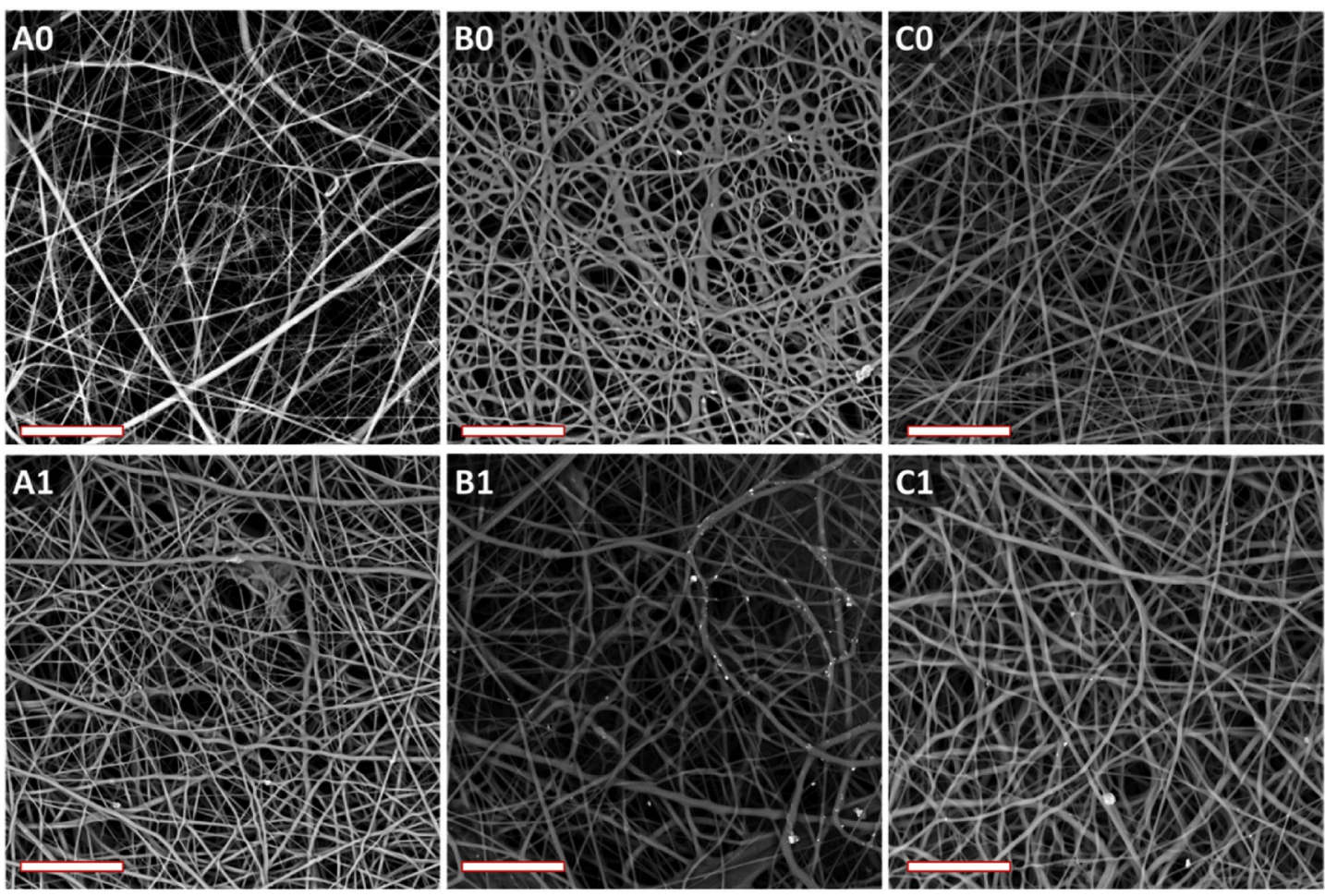

Fig. 5. SEM micrographs of A0, B0, C0, A1, B1 and C1, scale bar $=30 \mu \mathrm{m}$.

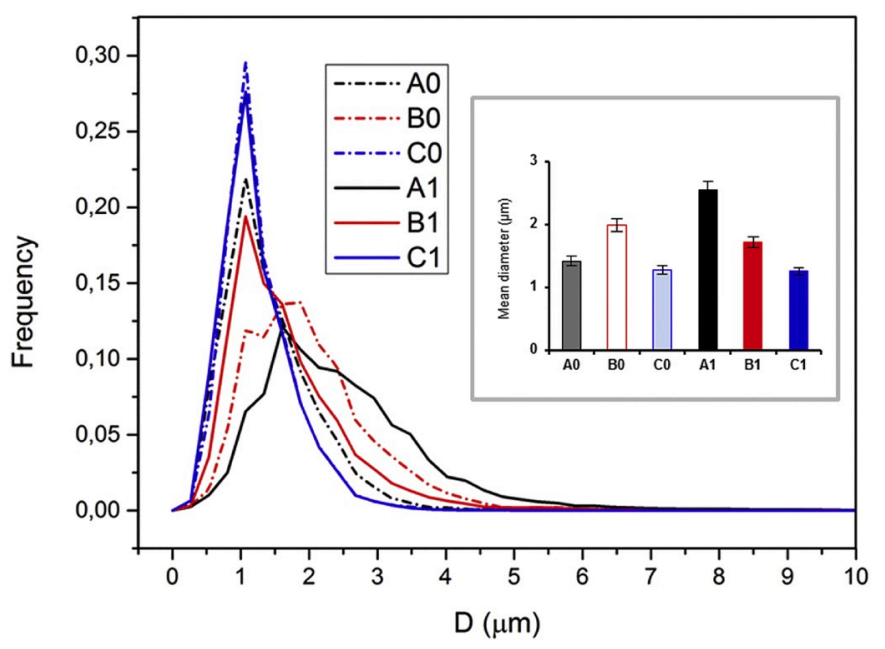

Fig. 6. Diameter size distribution of electrospun fibers, inset: mean diameters of the samples.

Generally, in a nanocomposite system, stiffness is strictly correlated to the extent of filler dispersion, i.e. interphase volume, whereas tensile strength is usually governed by interfacial adhesion between filler and matrix [47-49].

In electrospun fibrous mats, some structural features of the membranes, such as fibers diameter distribution, defects, hindered or promoted slipping of the fibers each other during tensile tests are known to affect ultimate properties of the samples [36,37]. Beyond these aspects, it is worth considering that PLA/PEO is an immiscible or partially miscible blend [50] and that CNF dispersion and affinity to the two polymer phases can obviously affect tensile properties. A-method is the best choice for processing PLA/PEO system, while being not appropriate for promoting $\mathrm{CNF}$ dispersion. Indeed, $\mathrm{CNF}$ is more dispersible in ethanol, due to the presence of $-\mathrm{OH}$ moieties in CNF structure, while tending to precipitate in acetone and chloroform. On the other hand, $\mathrm{PEO}$ is insoluble in ethanol, therefore in B0 and especially in B1 PEO islands arising from unmixing phenomena are clearly visible as bright dots in SEM morphology. Furthermore, the extreme heterogeneity of B-series membranes, with the coexistence of sprayed and fibrous areas, resulted in low performance materials, regardless of the presence or the absence of CNF. Using a three-solvent mixture allows on one hand PLA/PEO spinnability and on the other hand a more uniform CNF dispersion throughout the matrix.

In the perspective of using these membranes as biomimetic structures, such as tissue scaffolds, and wound dressings, swelling tests in water were carried out. The results, provided in Fig. 10, put into evidence that the presence of hydrophilic CNF promotes swelling degree. Consequently, ternary systems showed water uptake values higher than binary samples. Among binary systems, negligible differences can be found, with maximum uptake values equal to $100 \%$. In the early portion of the curves, absorption kinetics of A0 proved to be faster than those of $\mathrm{C} 0$ and especially B0. As regards ternary systems, C1 gave the best results, presumably due to the synergistic effect of CNF dispersion and fibrous structure (i.e. high surface area), followed by A1 and B1. Similarly to what seen in the case of binary blends, B1 showed a slower absorption in the initial portion of the curves, presumably because the electrospraying phenomena resulted into a bulkier structure. Moreover, after a certain time interval, the water uptake was found to decrease upon immersion time. This apparently strange behavior can be explained by considering that PEO is soluble in water. In B-series samples, the migration of PEO islands towards surface may have exposed them to solvation, thus resulting in mass loss.

\section{Conclusions}

This work elucidates the possibility to use an appropriate solvent mixture to overcome some difficulties related to the processing of nanocomposites when polymers and filler possess different solubility/ dispersability. Usually, the dispersion of nanocellulose in polymeric matrices is promoted by chemical functionalization of such 
CNF crystallinity $\mathrm{C}-\mathrm{O}$ bond (coupled with $\mathrm{C}-\mathrm{C}$ )

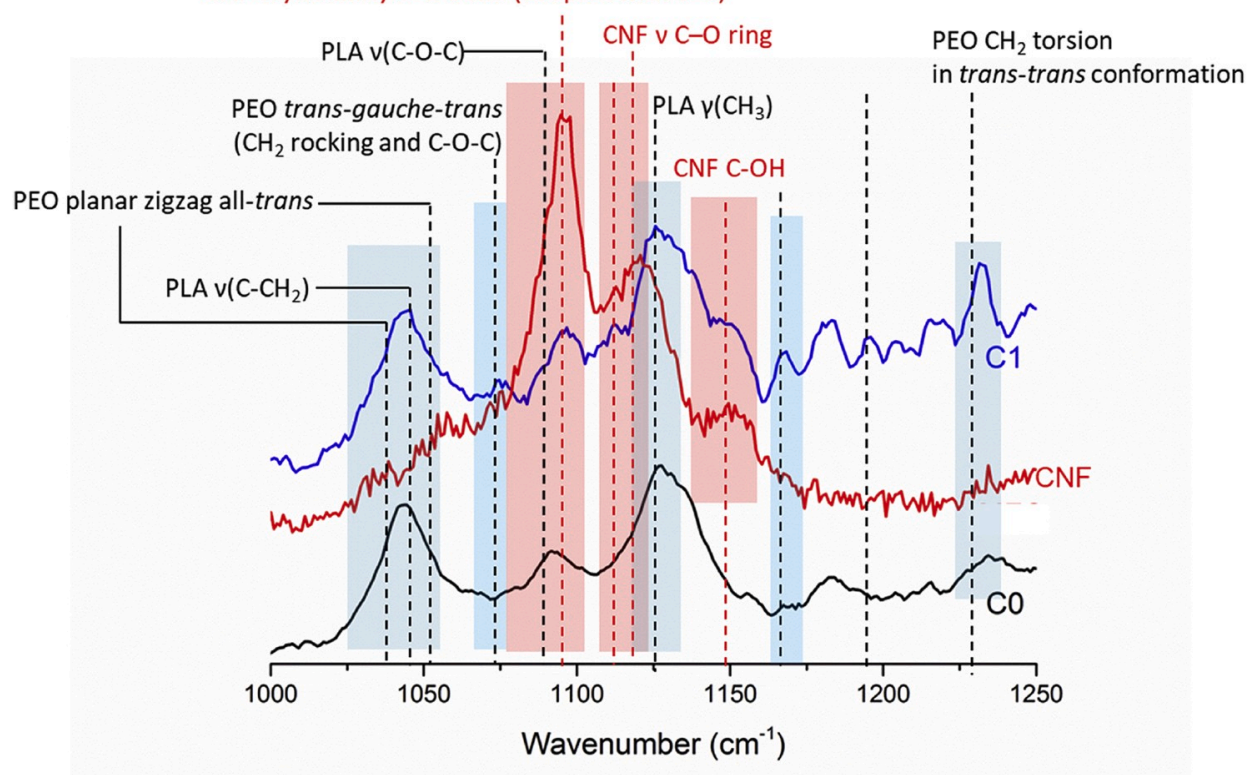

Fig. 7. Micro-Raman spectra of CNF, CO and C1recorded in the spectral range $1000-1250 \mathrm{~cm}^{-1}$.

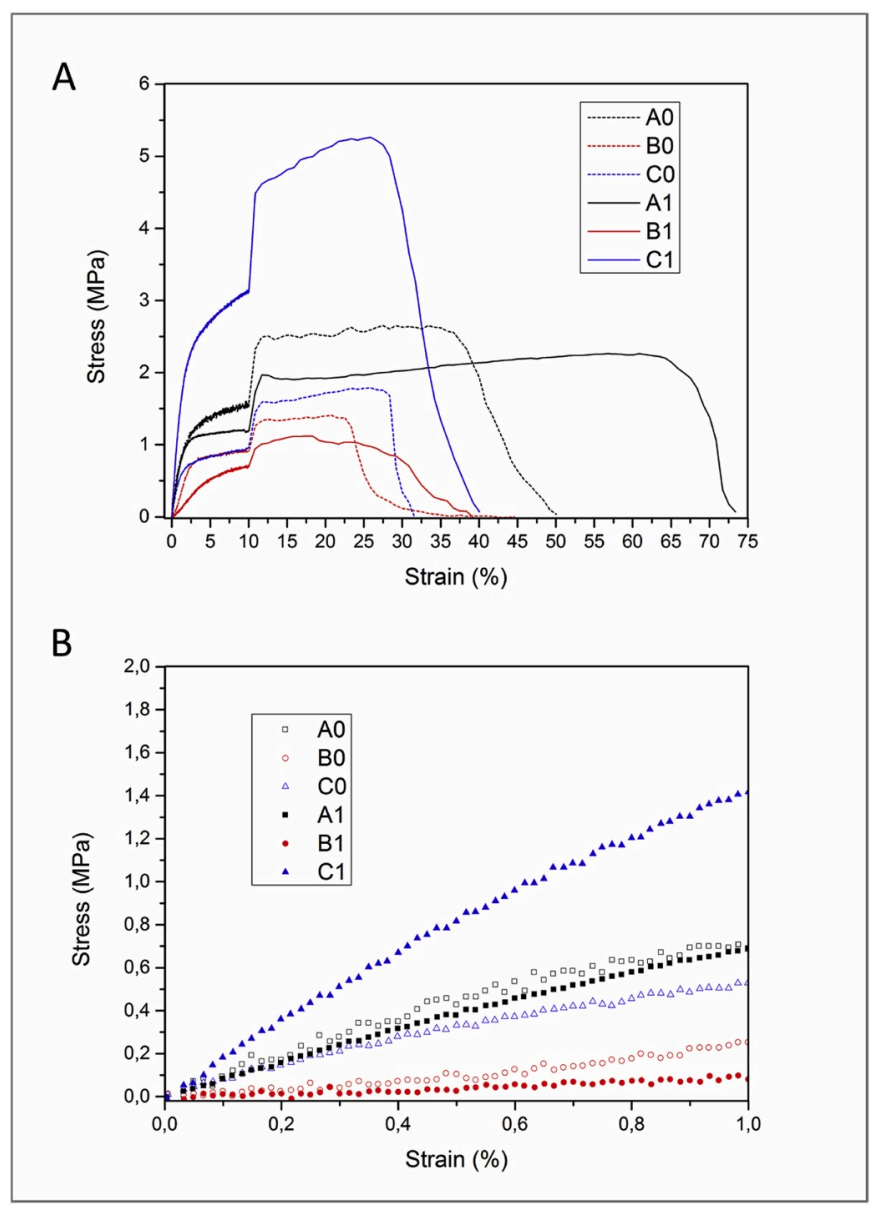

Fig. 8. Representative stress-strain curves of the materials investigated (A), low-strain region of each curve (B).

nanoparticles. This approach, however, involves time-consuming protocols and alters the hydrophilicity of CNCs that is crucial to biomedical applications. In the frame of this work we demonstrated that using
Table 2

Main results of tensile tests.

\begin{tabular}{lllll}
\hline Sample & E (MPa) & TS $(\mathrm{MPa})$ & EB $(\%)$ & Toughness $\left(\mathrm{MJ} / \mathrm{m}^{3}\right)$ \\
\hline A0 & $60 \pm 8$ & $2.55 \pm 0.03$ & $40 \pm 8$ & $0.95 \pm 0.02$ \\
B0 & $20 \pm 5$ & $1.36 \pm 0.05$ & $25 \pm 5$ & $0.26 \pm 0.01$ \\
C0 & $44 \pm 6$ & $1.52 \pm 0.10$ & $28 \pm 3$ & $0.29 \pm 0.01$ \\
A1 & $61 \pm 10$ & $2.11 \pm 0.05$ & $74 \pm 9$ & $1.37 \pm 0.02$ \\
B1 & $15 \pm 3$ & $1.01 \pm 0.01$ & $30 \pm 6$ & $0.28 \pm 0.01$ \\
C1 & $155 \pm 11$ & $5.42 \pm 0.02$ & $31 \pm 4$ & $1.41 \pm 0.02$ \\
\hline
\end{tabular}

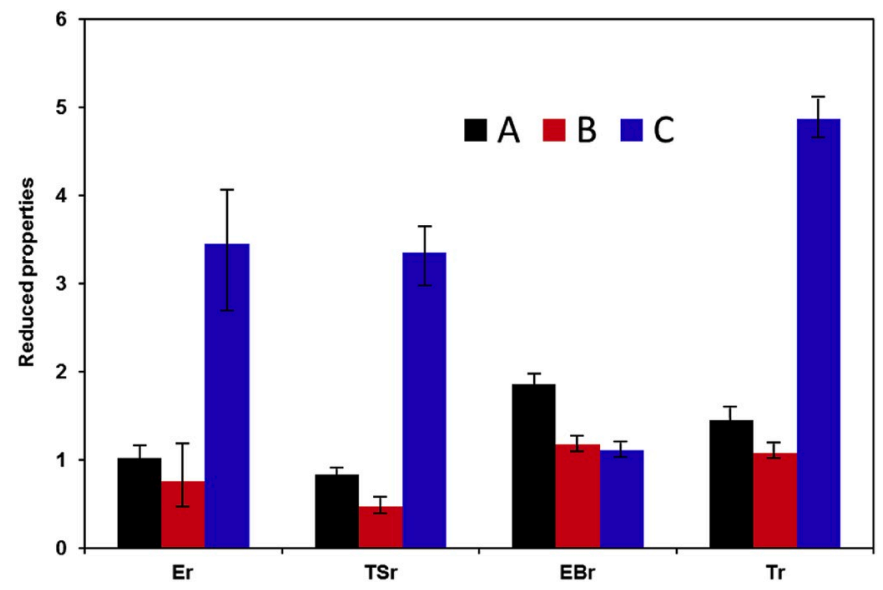

Fig. 9. Reduced mechanical properties for the composite membranes achieved by methods A, B and C. Reduced elastic modulus (Er), reduced tensile strength (TSr), reduced elongation at break (EBr), reduced toughness ( $\mathrm{Tr}$ ) are provided as ratio between the mean values of such properties measured for nanocomposites and those of the corresponding matrix.

chloroform/acetone/ethanol mixture allows preparing electrospun fibers based on PLA, PEO and CNCs by ensuring the electrospinnability of the polymers and the uniform filler dispersion. The process is extremely rapid, cheap and non-toxic, since all the solvents can be easily (and totally) removed by coagulation in ether. The choice of solvents mixture affects significantly the structure and the properties of the membranes. 


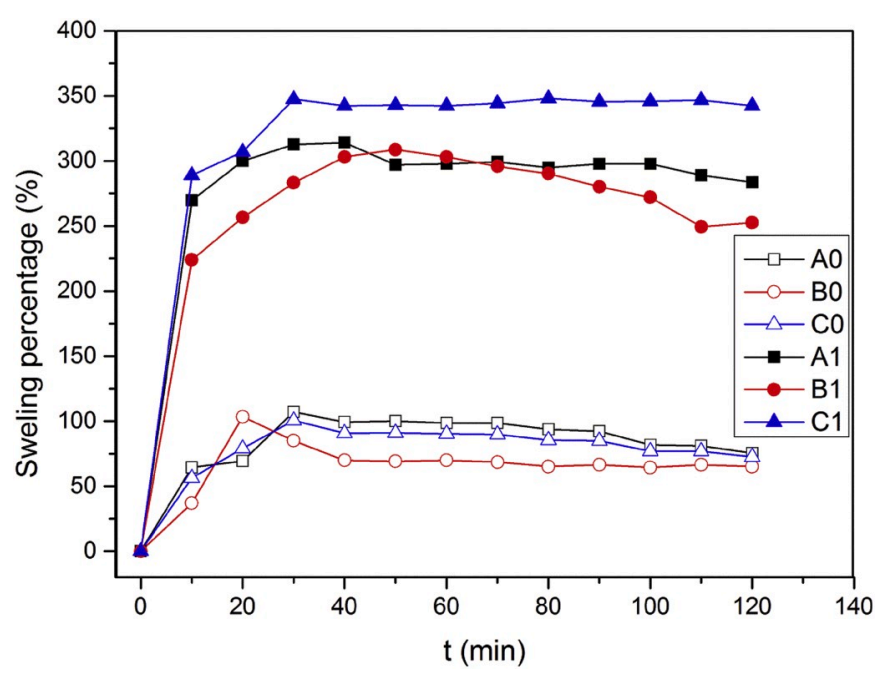

Fig. 10. Swelling tests.

Increments observed in mechanical properties $(+350 \%$ in stiffness, $+400 \%$ in TS and $+500 \%$ in toughness) and in swelling behavior (up to $+350 \%$ ) suggest that PLA/PEO/CNF electrospun fibers are potentially suitable for skin tissue engineering and wound dressing applications.

\section{Declaration of competing InterestCOI}

The authors declare that they have no known competing financial interests or personal relationships that could have appeared to influence the work reported in this paper.

\section{Acknowledgements}

The authors are grateful to Dr. Ramiro Rojas Escontrillas for having prepared and kindly supplied enzymatic cellulose nanofibers used in this study.

\section{Appendix A. Supplementary data}

Supplementary data to this article can be found online at https://doi. org/10.1016/j.polymertesting.2019.106182.

\section{References}

[1] R.A. Ilyas, S.M. Sapuan, M.L. Sanyang, M.R. Ishak, E.S. Zainudin, Nanocrystalline cellulose as reinforcement for polymeric matrix nanocomposites and its potential applications: a review, Curr. Anal. Chem. 14 (2018) 203-225, https://doi.org/ $10.2174 / 1573411013666171003155624$.

[2] M. Hietala, S. Sain, K. Oksman, Highly redispersible sugar beet nanofibers as reinforcement in bionanocomposites, Cellulose 24 (2017) 2177-2189, https://doi. org/10.1007/s10570-017-1245-6.

[3] M. Morreale, A. Liga, M. Mistretta, L. Ascione, F. Mantia, Mechanical, thermomechanical and reprocessing behavior of green composites from biodegradable polymer and wood flour, Materials 8 (2015) 7536-7548, https:// doi.org/10.3390/ma8115406.

[4] R. Scaffaro, F. Lopresti, A. Maio, L. Botta, S. Rigogliuso, G. Ghersi, Electrospun PCL/GO-g-PEG structures: processing-morphology-properties relationships, Compos Part A Appl. Sci. Manuf. 92 (2017), https://doi.org/10.1016/j. compositesa.2016.11.005.

[5] R. Scaffaro, A. Maio, E.F. Gulino, B. Megna, Structure-property relationship of PLAOpuntia Ficus Indica biocomposites, Compos. B Eng. 167 (2019) 199-206, https:// doi.org/10.1016/j.compositesb.2018.12.025.

[6] R. Scaffaro, L. Botta, F. Lopresti, A. Maio, F. Sutera, Polysaccharide nanocrystals as fillers for PLA based nanocomposites, Cellulose 24 (2017), https://doi.org/ 10.1007/s10570-016-1143-3.

[7] R. Scaffaro, A. Maio, F. Lopresti, L. Botta, Nanocarbons in electrospun polymeric nanomats for tissue engineering: a review, Polymers 9 (2017), https://doi.org/ 10.3390/polym9020076.

[8] R. Scaffaro, A. Maio, Integrated ternary bionanocomposites with superior mechanical performance via the synergistic role of graphene and plasma treated carbon nanotubes, Compos. B Eng. (2019), https://doi.org/10.1016/j. compositesb.2019.03.076.

[9] F.V. Ferreira, L.P. Souza, T.M.M. Martins, J.H. Lopes, B.D. Mattos, M. Mariano, et al., Nanocellulose/bioactive glass cryogels as scaffolds for bone regeneration, Nanoscale (2019), https://doi.org/10.1039/C9NR05383B.

[10] S. Sinha Ray, Polylactide-based bionanocomposites: a promising class of hybrid materials, Acc. Chem. Res. 45 (2012) 1710-1720, https://doi.org/10.1021/ ar3000376.

[11] Z. Song, H. Xiao, Y. Zhao, Hydrophobic-modified nano-cellulose fiber/PLA biodegradable composites for lowering water vapor transmission rate (WVTR) of paper, Carbohydr. Polym. 111 (2014) 442-448, https://doi.org/10.1016/j. carbpol.2014.04.049.

[12] N.L. García, M. Lamanna, N. D’Accorso, A. Dufresne, M. Aranguren, S. Goyanes, Biodegradable materials from grafting of modified PLA onto starch nanocrystals, Polym. Degrad. Stab. 97 (2012) 2021-2026, https://doi.org/10.1016/j. polymdegradstab.2012.03.032.

[13] M. Norouzi, S.M. Boroujeni, N. Omidvarkordshouli, M. Soleimani, Advances in skin regeneration: application of electrospun scaffolds, Adv. Healthc. Mater. 4 (2015), https://doi.org/10.1002/adhm.201500001.

[14] R. Scaffaro, L. Botta, A. Maio, G. Gallo, PLA graphene nanoplatelets nanocomposites: physical properties and release kinetics of an antimicrobial agent, Compos. B Eng. 109 (2017) 139-146, https://doi.org/10.1016/j. compositesb.2016.10.058.

[15] R. Scaffaro, F. Lopresti, A. Maio, F. Sutera, L. Botta, Development of polymeric functionally graded scaffolds: a brief review, J. Appl. Biomater. Funct. Mater. 15 (2017), https://doi.org/10.5301/jabfm.5000332.

[16] I. Armentano, N. Bitinis, E. Fortunati, S. Mattioli, N. Rescignano, R. Verdejo, et al., Multifunctional nanostructured PLA materials for packaging and tissue engineering, Prog. Polym. Sci. 38 (2013) 1720-1747, https://doi.org/10.1016/j. progpolymsci.2013.05.010.

[17] R. Scaffaro, F. Lopresti, L. Botta, Preparation, characterization and hydrolytic degradation of PLA/PCL co-mingled nanofibrous mats prepared via dual-jet electrospinning, Eur. Polym. J. 96 (2017) 266-277, https://doi.org/10.1016/j eurpolymj.2017.09.016.

[18] P. Kuppan, S. Sethuraman, U.M. Krishnan, Interaction of human smooth muscle cells on random and aligned nanofibrous scaffolds of PHBV and PHBV-gelatin, Int. J. Polym. Mater. Polym. Biomater. 65 (2016) 816-825, https://doi.org/10.1080/ 00914037.2016.1163562.

[19] R. Scaffaro, F. Lopresti, A. Sutera, L. Botta, R.M. Fontana, G. Gallo, Plasma modified PLA electrospun membranes for actinorhodin production intensification in Streptomyces coelicolor A3(2) immobilized-cell cultivations, Colloids Surfaces B Biointerfaces 157 (2017) 233-241, https://doi.org/10.1016/j. colsurfb.2017.05.060.

[20] A.J. Bauer, Y. Wu, B. Li, Electrospun poly ( $\varepsilon$-caprolactone)/Polyhedral oligomeric silsesquioxane-based copolymer blends: evolution of fiber internal structures, Macromol. Biosci. 16 (2016) 816-825.

[21] C. Zhang, M.R. Salick, T.M. Cordie, T. Ellingham, Y. Dan, L.-S. Turng, Incorporation of poly(ethylene glycol) grafted cellulose nanocrystals in poly(lactic acid) electrospun nanocomposite fibers as potential scaffolds for bone tissue engineering, Mater. Sci. Eng. C 49 (2015) 463-471, https://doi.org/10.1016/j. msec. 2015.01.024.

[22] N. Naseri, A.P. Mathew, K. Oksman, Electrospinnability of bionanocomposites with high nanocrystal loadings: the effect of nanocrystal surface characteristics, Carbohydr. Polym. 147 (2016) 464-472, https://doi.org/10.1016/j. carbpol.2016.04.018.

[23] T. Moberg, K. Sahlin, K. Yao, S. Geng, G. Westman, Q. Zhou, et al., Rheological properties of nanocellulose suspensions: effects of fibril/particle dimensions and surface characteristics, Cellulose 24 (2017) 2499-2510, https://doi.org/10.1007/ s10570-017-1283-0.

[24] Y. Xue, Z. Mou, H. Xiao, Nanocellulose as a sustainable biomass material: structure $\{$,$\} properties \{$,$\} present status and future prospects in biomedical applications,$ Nanoscale 9 (2017) 14758-14781, https://doi.org/10.1039/C7NR04994C.

[25] M. Jorfi, E.J. Foster, Recent advances in nanocellulose for biomedical applications, J. Appl. Polym. Sci. 132 (2015), https://doi.org/10.1002/app.41719.

[26] F.V. Ferreira, G.N. Trindade, L.M.F. Lona, J.S. Bernardes, R.F. Gouveia, LDPEbased composites reinforced with surface modified cellulose fibres: 3D morphological and morphometrical analyses to understand the improved mechanical performance, Eur. Polym. J. 117 (2019) 105-113, https://doi.org/ 10.1016/j.eurpolymj.2019.05.005.

[27] F.V. Ferreira, M. Mariano, I.F. Pinheiro, E.M. Cazalini, D.H.S. Souza, L.S. S. Lepesqueur, et al., Cellulose nanocrystal-based poly(butylene adipate-coterephthalate) nanocomposites covered with antimicrobial silver thin films, Polym. Eng. Sci. 59 (2019) E356-E365, https://doi.org/10.1002/pen.25066.

[28] U. Edlund, T. Lagerberg, E. Ålander, Admicellar polymerization coating of CNF enhances integration in degradable nanocomposites, Biomacromolecules 20 (2019) 684-692, https://doi.org/10.1021/acs.biomac.8b01318.

[29] K. Oksman, Y. Aitomäki, A.P. Mathew, G. Siqueira, Q. Zhou, S. Butylina, et al., Review of the recent developments in cellulose nanocomposite processing, Compos. Part A Appl. Sci. Manuf. 83 (2016) 2-18, https://doi.org/10.1016/j. compositesa.2015.10.041.

[30] B. Yang, Z. Dai, S.-Y. Ding, C.E. Wyman, Enzymatic hydrolysis of cellulosic biomass, Biofuels 2 (2011) 421-450, https://doi.org/10.4155/bfs.11.116.

[31] G. Lo Re, J. Engström, Q. Wu, E. Malmström, U.W. Gedde, R.T. Olsson, et al., Improved cellulose nanofibril dispersion in melt-processed polycaprolactone nanocomposites by a latex-mediated interphase and wet feeding as LDPE 
alternative, ACS Appl. Nano Mater. 1 (2018) 2669-2677, https://doi.org/10.1021/ acsanm.8b00376.

[32] M. Henriksson, G. Henriksson, L.A. Berglund, T. Lindström, An environmentally friendly method for enzyme-assisted preparation of microfibrillated cellulose (MFC) nanofibers, Eur. Polym. J. 43 (2007) 3434-3441, https://doi.org/10.1016/ j.eurpolymj.2007.05.038.

[33] A. Maio, R. Scaffaro, L. Lentini, A. Palumbo Piccionello, I. Pibiri, Perfluorocarbons-graphene oxide nanoplatforms as biocompatible oxygen reservoirs, Chem. Eng. J. 334 (2018) 54-65, https://doi.org/10.1016/j. cej.2017.10.032.

[34] A. Maio, D. Giallombardo, R. Scaffaro, A. Palumbo Piccionello, I. Pibiri, Synthesis of a fluorinated graphene oxide-silica nanohybrid: improving oxygen affinity, RSC Adv. 6 (2016), https://doi.org/10.1039/c6ra02585d.

[35] N.A. Hotaling, K. Bharti, H. Kriel, C.G. Simon, DiameterJ: a validated open source nanofiber diameter measurement tool, Biomaterials 61 (2015) 327-338, https:// doi.org/10.1016/j.biomaterials.2015.05.015.

[36] R. Scaffaro, F. Lopresti, A. Maio, L. Botta, S. Rigogliuso, G. Ghersi, Electrospun PCL/GO-g-PEG structures: processing-morphology-properties relationships, Compos Part A Appl. Sci. Manuf. 92 (2017) 97-107, https://doi.org/10.1016/j. compositesa.2016.11.005.

[37] R. Scaffaro, A. Maio, F. Lopresti, Effect of graphene and fabrication technique on the release kinetics of carvacrol from polylactic acid, Compos. Sci. Technol. 169 (2019), https://doi.org/10.1016/j.compscitech.2018.11.003.

[38] A. Frenot, I.S. Chronakis, Polymer nanofibers assembled by electrospinning, Curr. Opin. Colloid Interface Sci. 8 (2003) 64-75, https://doi.org/10.1016/S1359-0294 (03)00004-9.

[39] J.E. Oliveira, E.A. Moraes, J.M. Marconcini, C. Mattoso LH, G.M. Glenn, E. S. Medeiros, Properties of poly(lactic acid) and poly(ethylene oxide) solvent polymer mixtures and nanofibers made by solution blow spinning, J. Appl. Polym. Sci. 129 (2013) 3672-3681, https://doi.org/10.1002/app.39061.

[40] J.H. Park, Y.H. Bae, Hydrogels based on poly(ethylene oxide) and poly (tetramethylene oxide) or poly(dimethyl siloxane): synthesis, characterization, in vitro protein adsorption and platelet adhesion, Biomaterials 23 (2002) 1797-1808, https://doi.org/10.1016/S0142-9612(01)00306-4.
[41] U.P. Agarwal, S.A. Ralph, R.S. Reiner, C. Baez, Probing crystallinity of never-dried wood cellulose with Raman spectroscopy, Cellulose 23 (2016) 125-144, https:// doi.org/10.1007/s10570-015-0788-7.

[42] R. Basile, L. Bergamonti, F. Fernandez, C. Graiff, A. Haghighi, C. Isca, et al., Bioinspired consolidants derived from crystalline nanocellulose for decayed wood, Carbohydr. Polym. 202 (2018) 164-171, https://doi.org/10.1016/j. carbpol.2018.08.132.

[43] K.K. Gupta, N. Pal, P.K. Mishra, P. Srivastava, S. Mohanty, P. Maiti, 5-Florouracilloaded poly(lactic acid)-poly(caprolactone) hybrid scaffold: potential chemotherapeutic implant, J. Biomed. Mater. Res. A 102 (2014) 2600-2612, https://doi.org/10.1002/jbm.a.34932.

[44] M. Richard-Lacroix, C. Pellerin, Raman spectroscopy of individual poly(ethylene oxide) electrospun fibers: effect of the collector on molecular orientation, Vib. Spectrosc. 91 (2017) 92-98, https://doi.org/10.1016/j.vibspec.2016.09.002.

[45] A. Boschin, P. Johansson, Characterization of NaX (X: TFSI, FSI) - PEO based solid polymer electrolytes for sodium batteries, Electrochim. Acta 175 (2015) 124-133, https://doi.org/10.1016/j.electacta.2015.03.228.

[46] A. Arya, A.L. Sharma, Insights into the use of polyethylene oxide in energy storage/ conversion devices: a critical review, J. Phys. D Appl. Phys. 50 (2017), https://doi. org/10.1088/1361-6463/aa8675.

[47] A. Maio, R. Fucarino, R. Khatibi, S. Rosselli, M. Bruno, R. Scaffaro, A novel approach to prevent graphene oxide re-aggregation during the melt compounding with polymers, Compos. Sci. Technol. 119 (2015) 131-137, https://doi.org/ 10.1016/j.compscitech.2015.10.006.

[48] R. Scaffaro, A. Maio, A green method to prepare nanosilica modified graphene oxide to inhibit nanoparticles re-aggregation during melt processing, Chem. Eng. J. 308 (2017) 1034-1047, https://doi.org/10.1016/j.cej.2016.09.131.

[49] R. Scaffaro, A. Maio, Optimization of two-step techniques engineered for the preparation of polyamide 6 graphene oxide nanocomposites, Compos. B Eng. 165 (2019) 55-64, https://doi.org/10.1016/j.compositesb.2018.11.107.

[50] R. Scaffaro, A. Maio, Re G. Lo, A. Parisi, A. Busacca, Advanced piezoresistive sensor achieved by amphiphilic nanointerfaces of graphene oxide and biodegradable polymer blends, Compos. Sci. Technol. 156 (2018) 166-176, https://doi.org/ 10.1016/j.compscitech.2018.01.008. 